\title{
Effect of an intrauterine silk thread in the rat on the amino acid content of the intraluminal fluid
}

\author{
M. Roy Chaudhury and R. R. Chaudhury \\ Department of Obstetrics and Gynaecology, Chulalongkorn Hospital Medical School, \\ Bangkok, Thailand
}

The mechanism of the contraceptive effect of an intrauterine silk thread in the rat uterus is not clearly understood. It has been suggested that such a device may act by releasing into the intraluminal fluid a blastotoxic substance which destroys the blastocyst before implantation (Batta \& Chaudhury 1968a, b; Marston \& Kelly, 1969; De Boer, Anderson \& Melampy, 1970; Eckstein, 1970). In the present study the concentrations of amino acids in the intraluminal fluid of a horn containing a silk thread were compared to those in fluid from uteri without any devices.

Cyclic adult Charles Foster rats were anaesthetized with ether and a 3/0 silk thread suture was introduced into the right horn of the uterus as described by Doyle \& Margolis (1963). Fluid was aspirated from both uterine horns at oestrus and stored at $-40^{\circ} \mathrm{C}$ until analysis. The amino acid content of the samples was determined with an Aminoacid Analyzer after precipitation of the proteins by sulphosalicylic acid.

It can be seen from the results in Table 1 that some amino acids were present only in the fluid from the uterine horn containing the silk thread, and that the concentrations of others were increased in these samples.

Table 1. The mean \pm S.D. amino acid content $(\mu \mathrm{mol} / \mathrm{ml})$ of uterine intraluminal fluid of rats with (experimental horn) or without (control horn) an intrauterine silk thread

\begin{tabular}{|c|c|c|c|}
\hline Amino acid & Control horn & Experimental horn & Significance \\
\hline Citrulline & 0 & $13 \cdot 9 \pm 8 \cdot 7$ & \\
\hline Methionine & 0 & $6 \cdot 6 \pm 7 \cdot 1$ & \\
\hline Histidine & $\mathbf{0}$ & $11 \cdot 5 \pm 5 \cdot 3$ & \\
\hline Ethanolamine & 0 & $30 \cdot 2 \pm 26 \cdot 7$ & \\
\hline Taurine & $151 \cdot 6 \pm 63 \cdot 5$ & $833 \cdot 0 \pm 112 \cdot 7$ & $P<0.001$ \\
\hline Half cystine & $3.9 \pm 3.5$ & $16 \cdot 2 \pm 3 \cdot 8$ & $P<0.005$ \\
\hline Proline & $3 \cdot 6 \pm 6 \cdot 1$ & $46 \cdot 3 \pm 16 \cdot 1$ & $P<0.005$ \\
\hline Lysine & $5.9 \pm 2.4$ & $57 \cdot 6 \pm 24 \cdot 2$ & $P<0.01$ \\
\hline Valine & $2 \cdot 1 \pm 3 \cdot 6$ & $28.9 \pm 14 \cdot 5$ & $P<0.02$ \\
\hline Tyrosine & $0.8 \pm 1.4$ & $19 \cdot 6 \pm 10.9$ & $P<0.02$ \\
\hline Arginine & $1 \cdot 4 \pm 4 \cdot 1$ & $34 \cdot 2 \pm 20 \cdot 5$ & $P<0.02$ \\
\hline Threonine & $6 \cdot 0 \pm 0 \cdot 1$ & $31 \cdot 7 \pm 14 \cdot 0$ & $P<0.02$ \\
\hline Glycine & $15 \cdot 6 \pm 3 \cdot 6$ & $51 \cdot 6 \pm 18 \cdot 4$ & $P<0.02$ \\
\hline Isoleucine & $2 \cdot 7 \pm 0.1$ & $25 \cdot 0 \pm 14 \cdot 3$ & $P<0.02$ \\
\hline Glutamic acid & $25 \cdot 1 \pm 13 \cdot 5$ & $72 \cdot 5 \pm 22 \cdot 2$ & $P<0.02$ \\
\hline Alanine & $12 \cdot 0 \pm 5 \cdot 0$ & $58 \cdot 3 \pm 35 \cdot 5$ & $P<0.05$ \\
\hline Leucine & $5.6 \pm 1.4$ & $52 \cdot 4 \pm 31 \cdot 8$ & $P<0.05$ \\
\hline Serine & $10 \cdot 1 \pm 3 \cdot 0$ & $51 \cdot 2 \pm 31 \cdot 7$ & $P<0.05$ \\
\hline Aspartic acid & $10.9 \pm 6.4$ & $23.4 \pm 8 \cdot 5$ & $P<0.05$ \\
\hline Phenylalanine & $3.9 \pm 9.5$ & $18 \cdot 0 \pm 11 \cdot 1$ & N.S. \\
\hline Urea & $7458.3 \pm 1240.9$ & $8192 \cdot 2 \pm 1402 \cdot 5$ & N.S. \\
\hline Ornithine & $4 \cdot 5 \pm 1 \cdot 2$ & $11 \cdot 3 \pm 6 \cdot 4$ & N.S. \\
\hline
\end{tabular}

The presence of an intrauterine device is associated with mild inflammatory changes (Segal, 1972), and the amino acid changes may be related to the resulting breakdown products. Nevertheless, one or more amino acids may be embryotoxic in the high concentrations found in the horn containing the 
silk thread. Breed, Peplow, Jefferies \& Eckstein (1973) have recently demonstrated that arginine, methionine, histidine, proline and valine are toxic to mouse morulae and blastocysts in vitro. In the present experiments, two of these amino acids, histidine and methionine, were absent from control intraluminal fluid, whilst arginine, proline and valine were present in very small concentrations. All these, and other, amino acids were present at significantly higher concentrations in fluid from the horns with an intrauterine silk thread. It is suggested that one or more of these amino acids may be responsible for the anti-implantation effect of the intrauterine device by exerting a blastotoxic effect on the zygotes.

We thank Dr Kosin Amatayakul of the Chiangmai Medical School for arranging for use of the auto-analyser at Malan, Chiangmai, and the Population Council, New York, for financial assistance.

\section{References}

BatTA, S.K. \& Chaudhury, R.R. (1968a) Antifertility effect of an intrauterine silk thread suture in rats with a connection between the two uterine horns. J. Reprod. Fert. 16, 371-379.

Batta, S.K. \& Chaudhury, R.R. (1968b) The antiimplantation property of intraluminal fluid in rats with an intrauterine silk thread suture. J. Reprod. Fert. 16, 145-146.

De Boer, K.F., Anderson, L.L. \& Melampy, R.M. (1970) Intrauterine device and embryonic survival in the rat. $J$. Reprod. Fert. 21, 343-346.

Breed, W.G., Peplow, P.V., Jefferies, C. \& Eckstein, P. (1973) Effect of uterine fluid from mice with
IUDs, and various chemical compounds, on mouse eggs in culture. Contraception 8, 343-356.

DOYLE, L.L. \& MARgolis, A.J. (1963) Intrauterine foreign body effect on pregnancy in rat. Science, N.Y. 139, 833-834.

EcksTeIN, P. (1970) Mechanisms of action of intrauterine contraceptive devices in women and other mammals. Br. Med. Bull. 26, 52-59.

Marston, J.H. \& Kelly, W.A. (1969) The effect of uterine anastomosis on the action of an intrauterine device in the rat. J. Endocr. 43, 95-103.

SEgaL, S.J. (1972) Intrauterine devices and their mechanism of action. Proc. 5th Nobel Symp., Control of Human Fertility, pp. 181-197. Stockholm.

Received 8 March 1976 